\title{
COOPERATION BETWEEN DEALATE QUEENS DURING COLONY FOUNDATION IN THE GREEN TREE ANT, OECOPHYLLA SMARAGDINA
}

\author{
By Christian Peeters ${ }^{1}$ And Alan N. Andersen ${ }^{2}$
}

\section{INTRODUCTION}

Colony reproduction in ants typically occurs through the foundation of a new nest by a single mated queen (haplometrosis), but sometimes involves several cooperating queens (pleometrosis). Pleometrosis enables successful colony foundation under adverse conditions (reviewed by Rissing and Pollock 1988), but it is not necessarily followed by polygyny once the colony has become established.

There exist two species of Oecophylla, both of which are conspicuous arboreal ants who weave living leaves into nests using larval silk. Although mature colonies can be extremely populous (half a million workers) and can be made up of hundreds of nests in many adjoining trees (Hölldobler and Wilson 1977, Hölldobler 1983), they are strictly monogynous (e.g. Hölldobler and Wilson 1983a, Greenslade 1971). Early observations on colony reproduction in the Asio-Australian species $O$. smaragdina by Dodd (1902) and Maxwell-Lefroy and Howlett (1909:233) have led to the assumption that a new colony is established by a single queen. However, various observations on the African species $O$. longinoda suggest that it is pleometrotic. Richards (1969) observed a group of 11 dealate queens together with many eggs and larvae on a window ledge, and Ledoux (1950) failed to collect single foundresses with brood. Here we document for the first time pleometrosis in $O$. smaragdina, and this behavior is discussed in the context of the monogynous state of established colonies.

\footnotetext{
'School of Biological Science, University of New South Wales, PO Box 1, Kensington N.S.W. 2033, Australia

${ }^{2}$ Division of Wildlife and Ecology, CSIRO Tropical Ecosystems Research Centre, PMB 44, Winnellie N.T. 0821, Australia

Manuscript received by the editor December 8, 1988.
} 


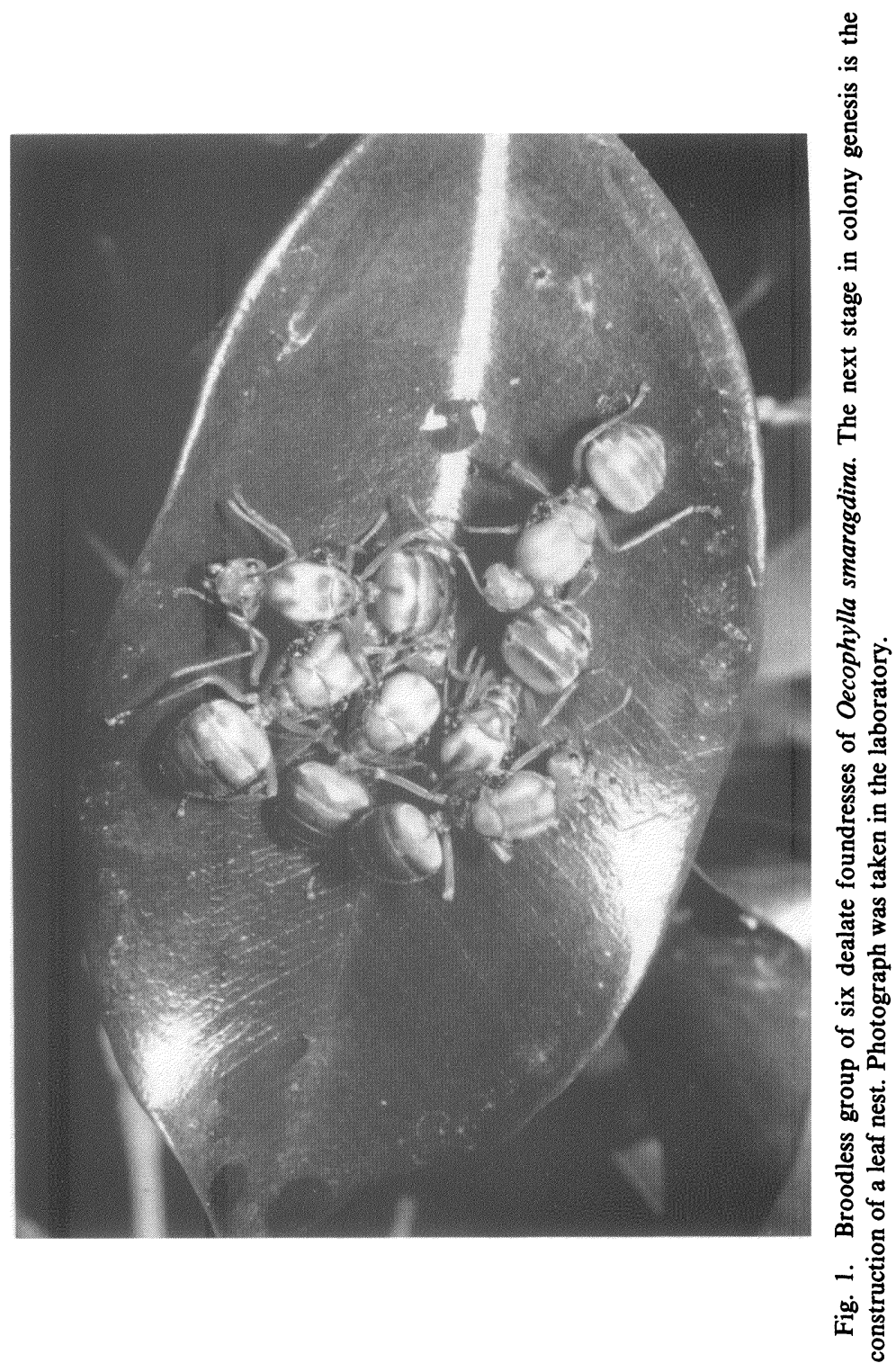




\section{OBSERVATIONS}

Three aggregations of dealate queens were collected in March 1987 from two locations in the coastal region of the Northern Territory, Australia: (i) suburban Darwin (colony QT-1, comprising at least 19 queens, plus eggs and larvae; colony QT-2, comprising 6 queens, plus eggs and larvae); (ii) eucalypt woodland at Ubirr, Kakadu National Park (colony QR-1, comprising 12 queens, 100 eggs, 117 larvae and $1 \mathrm{pupa}$ ). No further data are available on QT-1.

Colony QT-2 was completely enclosed inside a bent leaf sown together with silk, and occurred in an isolated shrub at a height of $1.5 \mathrm{~m}$. Seven days after collection, two minor workers appeared through a hole in the silk wall. In contrast, the queens of colony QR-1 were on the exposed surface of a leaf, crowded together over the brood (Fig. 1). When another leaf was placed close to the original one, the queens soon began to weave, and after three days closed walls of silk had been spun between the leaves. This nest remained sealed off until three weeks later, when several minor workers became active outside the nest. Major workers were never produced.

Colony QR-1 was taken back to Sydney for observations, and new leaf nests were built in small Ficus trees in the laboratory. The ants were fed on sugar water, small cockroaches, and wingless Drosophila. Nests were abandoned whenever the bound up leaves withered, so that several nest emigrations occurred in the laboratory. One of these began when over $\mathbf{4 0}$ workers first grouped at the new nest site, many of them holding leaves together. Weaving only started 2 hours later after several larvae of an appropriate age (silk is only produced by larvae at the beginning of the final instar; Hölldobler and Wilson 1983b) had been carried from the old nest. Four hours later some walls of silk had been spun, and although construction was not finished, eggs and small larvae were being carried across. The 10 surviving queens then walked across to the new nest over the next 19 hours. Each queen walked singly along the branches, apparently following a recruitment trail as their antennae were held forward, touching the substrate. They often stopped, but contact with the many workers walking in both directions along the same trail seemed to induce them to continue. The workers often remained near a queen whenever they encountered one. On a few occasions, single workers led queens out of the old nest by walking backwards and holding the queen's mandibles or the base of one 
antenna. As the queens were walking between nests, we noted that three of them were injured; each had parts of antennae and/or several limbs missing. One of these disappeared from the nest after a few days. However, direct aggression either among queens or between queens and minor workers was never observed. The minor workers frequently regurgitated to the queens, and licked their gasters, as described in Hölldobler and Wilson (1983a).

Males were never produced in the laboratory, indicating that all dealate queens were probably mated. Dissection of the spermathecae of nine queens confirmed this.

\section{Discussion}

Several mated queens cooperate to establish new colonies in $O$. smaragdina, although only a single queen is found in established colonies. Single dealate queens with brood have been collected (Dodd 1902; Maxwell-Lefroy and Howlett 1909, C. Lokkers pers. comm.; Vanderplank 1960 for $O$. longinoda), but it has never been established whether such behavior led to successful colony foundation. Ledoux (1950) reported that single dealate queens of $O$. longinoda could construct small sealed nests with their larvae in the laboratory, but he never found them in the field, and speculated that natural conditions were too hazardous for them to be successful.

The general advantages of pleometrosis include a faster increase in the number of workers in a colony, thus producing a foraging workforce more rapidly. This is important, because dealate queens do not forage and thus feed the first brood on their metabolized wing muscles and fat reserves. Until the workers start to bring in food from outside the nest, colony growth is strictly constrained. There are additional benefits of pleometrosis that are specific to Oecophylla. During the initial period, when a nest cannot yet be built because the first generation of larvae are too young to produce silk, the physical presence of several large queens serves as an effective shelter for the brood lying on the leaf. Later in the genesis of a colony, the construction of a leaf nest is clearly essential. Larvae and naked pupae require stable microclimatic conditions for their development, and one advantage of a leaf nest woven with silk is that the marked daily fluctuations in humidity and temperature are prevented (Ledoux 1950). The nests also provide shelter against rain and wind, and possibly various insect enemies. 
Cooperation between foundresses enables the quick construction of a leaf nest. Whereas a single queen is restricted to weave leaves that already overlap or are contiguous, the occurrence of several queens means that leaves can be bent and positioned into place through a separation of roles. Moreover, many queens initially mean more larvae, so that more silk is available and larger walls can be spun. Thus the initial nest can be bigger and better constructed, which delays the need for expansion and emigration.

No data were obtained in this study on the events leading from polygyny to monogyny. The presence of mutilated queens, however, is suggestive, because Rissing and Pollock (1988) mention that one strategy of supernumerary queen elimination is to injure rival queens, thereby making them less acceptable to workers. The major workers of $O$. smaragdina possibly play an important role in this elimination process.

As explained above, there are various advantages associated with queen cooperation at the beginning of colony foundation in $O$. smaragdina. However, these advantages cease once the first workers forage and there is an abundant supply of silk-spinning larvae. The import of food from outside leads to increased larval survival and egg production by queens. It should then be in the genetic interests of individual queens to eliminate their rivals so as to monopolize reproduction, thus leading to the monogynous state of mature colonies.

\section{SUMMARY}

In Oecophylla smaragdina, there is only one queen in each mature colony, and thus it is often thought that new colonies are started by a single foundress. However we collected small groups (6-19) of dealate queens and brood in the canopy of shrubs in the Northern Territory. These queens eventually wove communal leaf nests which were sealed off from the outside until the first workers started to forage. Cooperative colony foundation appears to have advantages specific to the leaf-nesting habit of Oecophylla, and in particular overcomes the difficulty faced by a single queen constructing a nest. Once a viable young colony has been established, the ecological benefits of cooperation cease, and it is in the genetic interest of an individual queen to eliminate her rivals so as to monopolize reproduction. 


\section{ACKNOWLEDGMENTS}

We thank Ross Crozier, Mark Elgar (UNSW), and Con Lokkers (James Cook University) for comments on the manuscript, and David Maitland for the photograph in Fig. 1. This work was supported by an Australian Research Grants Scheme grant to R. H. Crozier. This is TERC contribution no. 680.

\section{REFERENCES}

DodD, F. P. 1902. Notes on the Queensland green tree ants (Oecophylla smaragdina Fabr.). Victoria Nat. 18, 136-40.

Greenslade, P. J. 1971. Phenology of three ant species in the Solomon Islands. J. Aust. ent. Soc. 10, 241-52.

Hölldobler, B. 1983. Territorial behavior in the Green Tree Ant (Oecophylla smaragdina). Biotropica 15, 241-50.

Hölldobler, B., AND Wilson, E. O. 1977. Weaver Ants. Sci. Am. 237, 146-154. HölldDOBLER, B., AND WiLson, E. O. 1983a. Queen control in colonies of Weaver Ants (Hymenoptera:Formicidae). Ann. Entomol. Soc. Am. 76, 235-38.

Hölldobler, B., AND Wilson, E. O. 1983b. The evolution of communal nestweaving in ants. American Scientist 71, 490-99.

Ledoux, A. 1950. Recherche sur la biologie de la fourmi fileuse (Oecophylla longinoda Latr.). Annls Sci. nat. (Zool.). 12, 313-461.

MAXWEll-Lefroy, H., AND Howlett, F. M. 1909. Indian insect life, a manual of the insects of the plains. (Today \& Tomorrow's Printers \& Publishers: New Delhi.)

RICHARDS, O. W. 1969. Colony-founding in the ant Oecophylla longinoda (Latr.) (Hym., Formicidae). Entomologist's Monthly Magazine 105, 203.

Rissing, S. W., AND Pollock, G. B. 1988. Pleometrosis and polygyny in ants. In: Jeanne, R. L. (ed.) Interindividual behavioral variability in social insects. (Westview Press: Boulder, Colorado.) pp. 179-222.

VANDERPLANK, F. L. 1960. The bionomics and ecology of the red tree ant, Oecophylla sp., and its relationship to the coconut bug Pseudotheraptus wayi Brown (Coreidae). J. Anim. Ecol. 29, 15-33. 

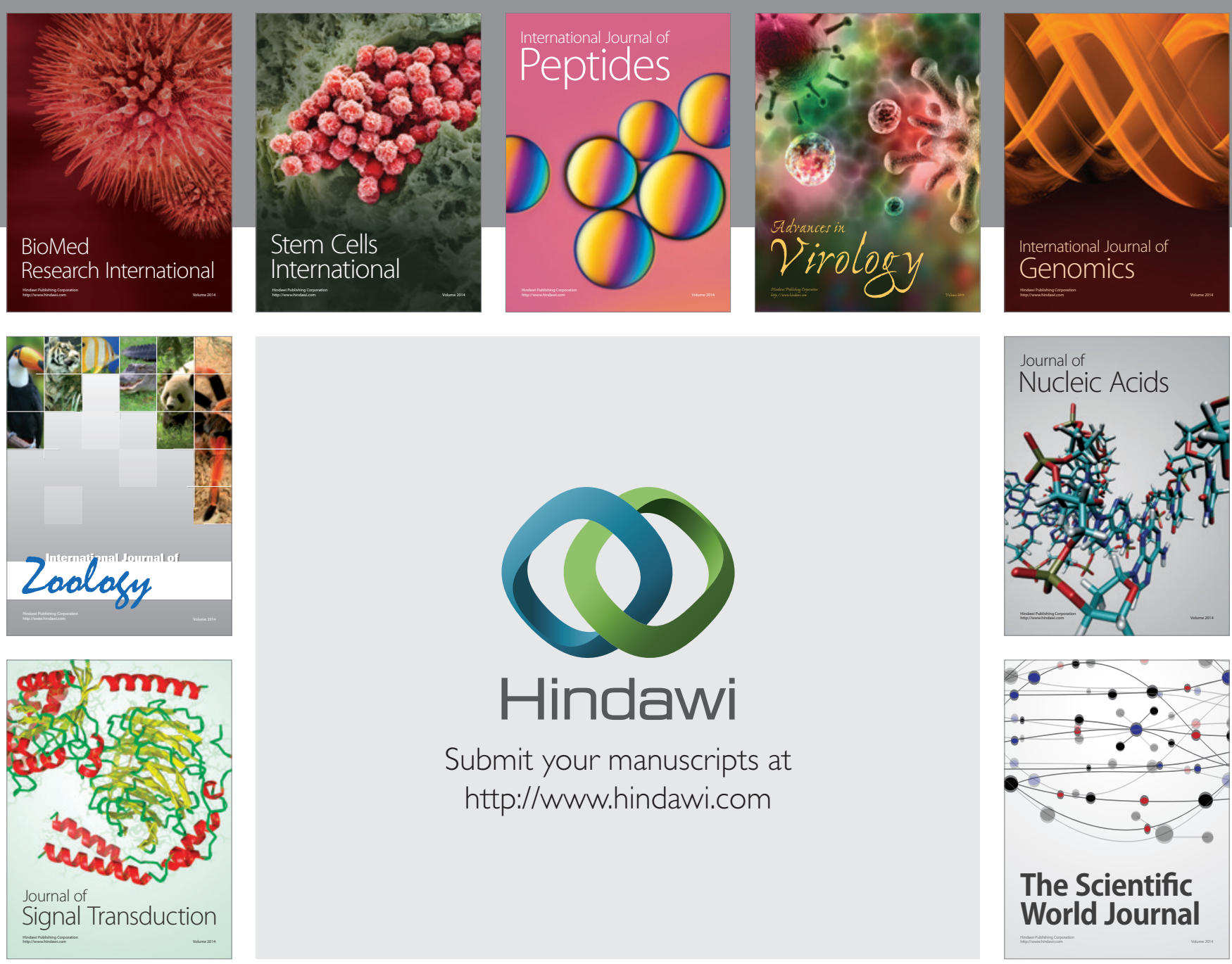

Submit your manuscripts at

http://www.hindawi.com
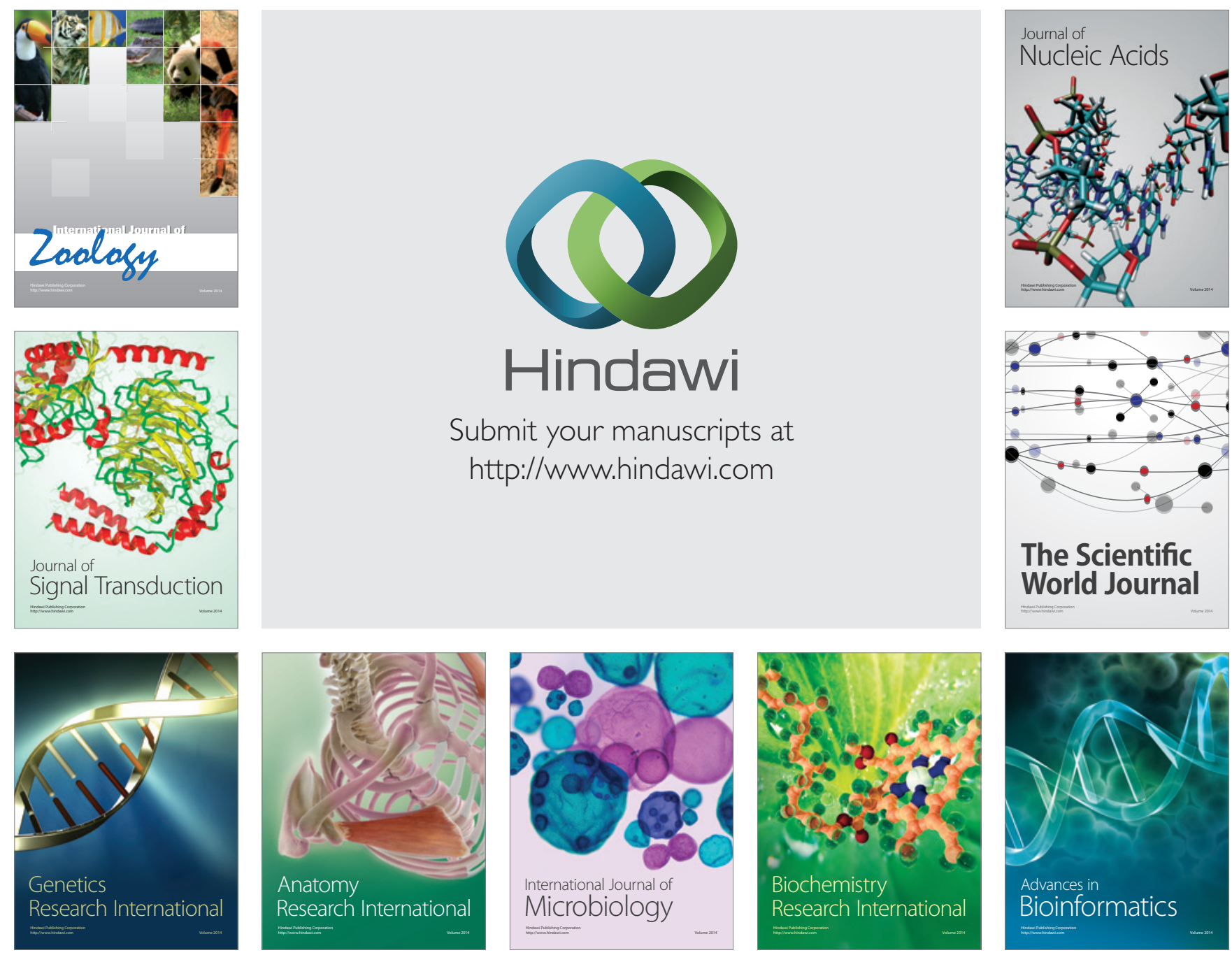

The Scientific World Journal
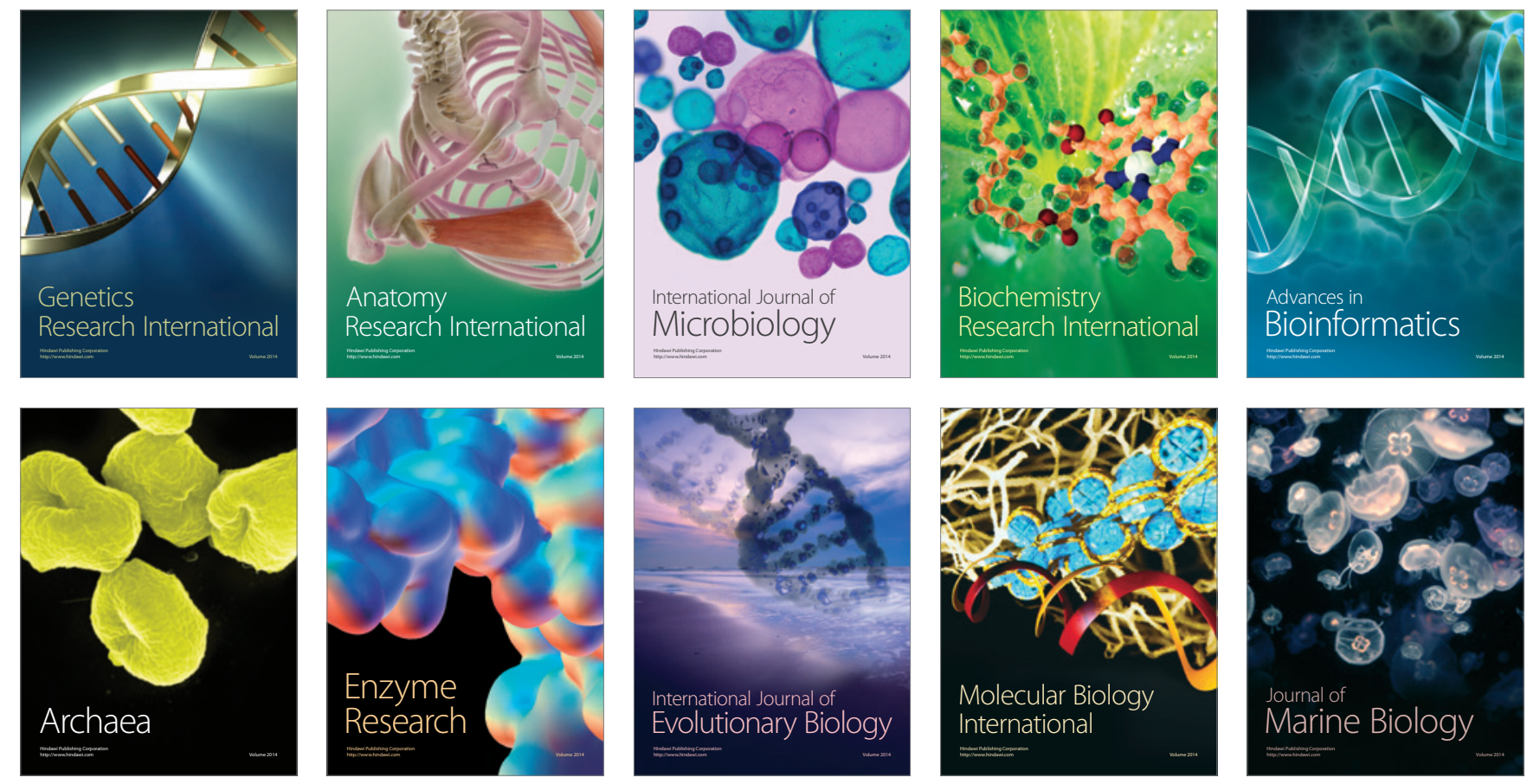